\title{
Flank sliding: a valve and a sentinel for paroxysmal eruptions and magma ascent at Mt.
} Etna

Giuseppe Pezzo ${ }^{1}$, Mimmo Palano ${ }^{2}$, Cristiano Tolomei ${ }^{1}$, Pasquale De Gori ${ }^{1}$, Stefano Calcaterra ${ }^{3}$, Piera Gambino $^{3}$, and Claudio Chiarabba ${ }^{1}$

${ }^{1}$ Istituto Nazionale di Geofisica e Vulcanologia, Osservatorio Nazionale Terremoti, via di Vigna Murata 605, 00143 Rome, Italy

${ }^{2}$ Istituto Nazionale di Geofisica e Vulcanologia, Sezione di Catania - Osservatorio Etneo, Piazza Roma, 2, 95123 Catania, Italy

${ }^{3}$ Italian Institute for Environmental Protection and Research - ISPRA, Via Vitaliano Brancati 60, Rome, Italy

\section{Supplemental Material}

Table of Contents

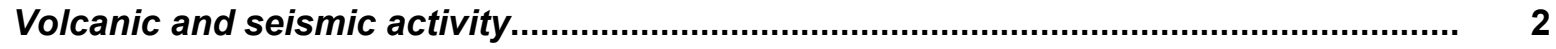

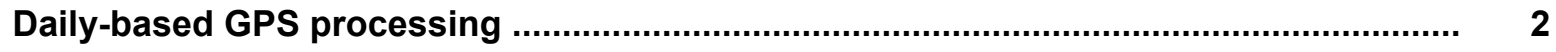

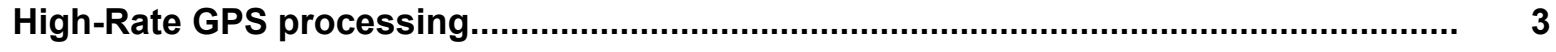

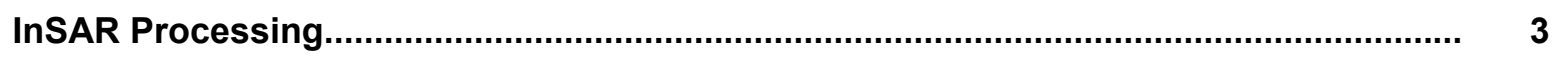

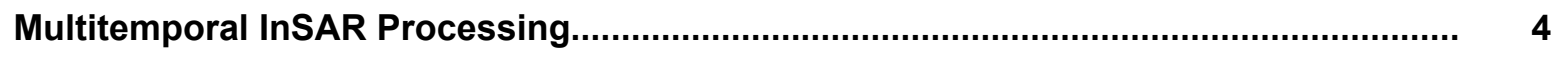

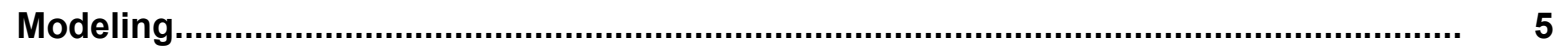

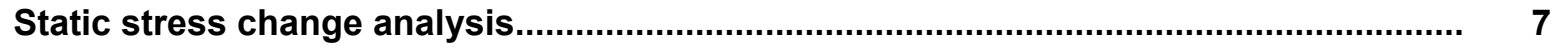

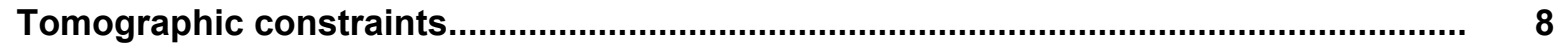

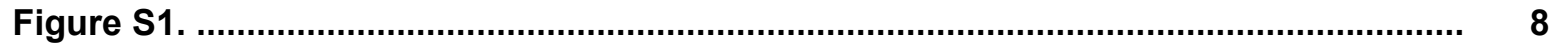

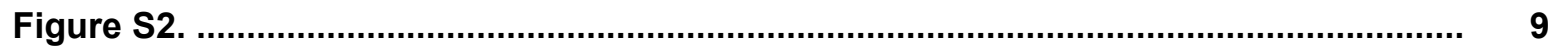

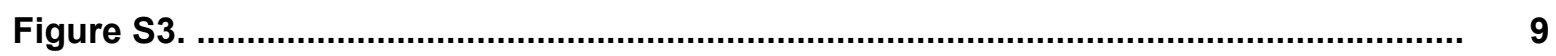

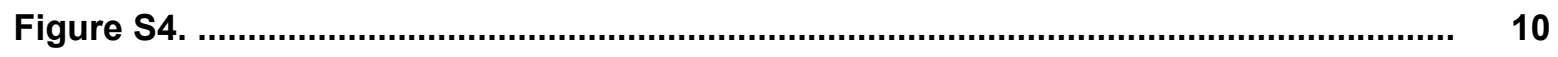

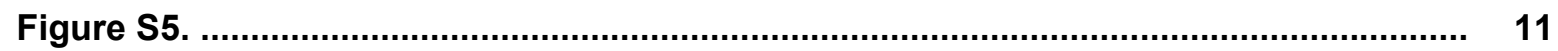

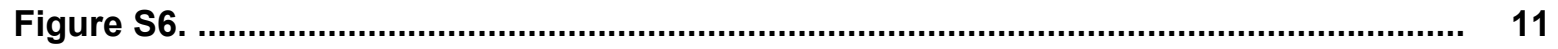

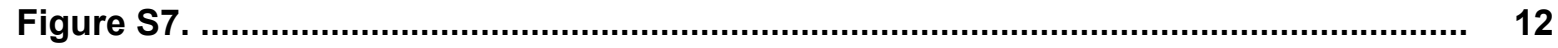

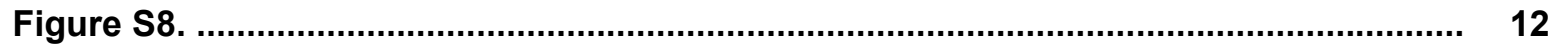

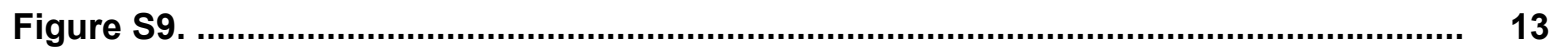

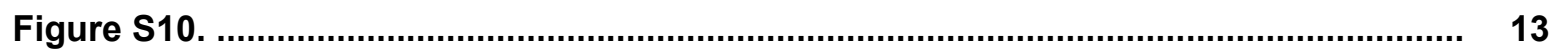


Figure S11.

Figure S12.

Figure S13.

Figure S14.

Table S1.

REFERENCES

19

\section{Volcanic and seismic activity}

On early 24 Dec 2018, after some weeks of low to moderate Strombolian explosions coupled with gas and ash emissions from the summit craters and modest lava flow (from the base of the New South-East Crater, hereinafter NSEC; Fig. 1B), a vigorous volcanic and seismic activity resumed. More in detail, volcanic activity started at 10.03 (UTC) with a vigorous ash emission at BN crater and was coupled with a marked baseline change at summit CGPS stations (Fig. 1C) and a co-eruptive offsets at all the stations located on the middle to upper flanks of the volcano. This activity evolved from sporadic to continuous ash emission at NEC also, coupled with an increasing seismic activity below the summit area (more than 200 shocks; maximum magnitude $=4$; Fig. $1 \mathrm{~A}$ ). Subsequently, a main eruptive fracture system opened on the south-eastern slope of NSEC, while a small eruptive fracture system opened northward (Fig. 1B). The former, propagating southeastward along the westward margin of the Valle del Bove, feds a vigorous Strombolian activity and some lava flows (Fig. 1B); the latter was active for less than 1 hour and showed a very weak Strombolian activity. In the following 24 hours, seismic activity shifted toward the eastern and south-eastern flank of the volcano. On 26 Dec. at 02:19 UTC, a shallow Mw4.9 earthquake dissected the lower SE flank of the volcano (Fig. 1A). This earthquake produced a significant deformation pattern close to the Fiandaca fault system, evidencing a prevailing right lateral strikeslip kinematics of the fault system (Fig. 1A). CGPS station closely installed to the fault system recorded a coseismic deformation of $\sim 7 \mathrm{~cm}$ while no deformation related to this earthquake was observed at stations located to the summit area (Figs. 1C). Ash emissions from BN and from the main eruptive fracture continued, with decreasing intensity along $25 \mathrm{Dec}$., while the lava emissions stopped on $27 \mathrm{Dec}$. Furthermore, in the following months a large sector of the eastern flank (mainly its northern half) continued to move seaward with decreasing rates.

\section{Daily-based GPS processing}

Raw CGPS observations, collected at the networks managed by INGV-OE and ISPRA (Fig. S1) and spanning the 1 Dec. 2018 - 28 Jun. 2019 time interval, were processed by using the GAMIT/GLOBK software (Herring et al. 2018). To improve the overall configuration of the network and tie the regional measurements to an external global reference frame, data coming from 10 continuously operating IGS stations (BRUX, TORI, GENO, GRAS, GRAZ, JOZE, MATE, IENG, 
NOT1 and ZIMM) were introduced in the processing. In a first step, we used the daily double differenced GPS phase observations to estimate both station coordinates and Earth orientation parameters. In this step, the observations were weighted according to the elevation angle, for which a cut-off angle of $10^{\circ}$ was chosen. Because of the mixed antenna-receiver types used in the analyzed network, we used the latest absolute receiver antenna models by the IGS. In addition, we adopted the Saastamoinen (1972) atmospheric zenith delay models, coupled with the Global Mapping Functions (Böhm et al., 2006) for the neutral atmosphere. Estimated CGPS daily time series as well as displacement and velocity fields for all the time interval analyzed in the study have been referred to a local reference frame (Palano et al., 2010).

\section{High-Rate GPS processing}

In order to provide additional details on the temporal evolution of the main ground deformation field related both to the dike intrusion and the Mw4.9 earthquake, occurred on 24 and 26 December 2018, respectively, we used the kinematic module of the GAMIT/GLOBK software, namely TRACK (Herring et al., 2018), to compute the high-rate solutions of some selected CGPS stations. TRACK performs relative kinematic positioning among sites: in our analysis, we estimated the distance change (sampled at 30 seconds) between the EPDN-EINT and EBDA-ELIN CGPS stations. TRACK uses floating point LC observations and the Melbourne-Wübbena wide-lane combination (Wübbena, 1988), with ionosphere delay constraints, to determine integer ambiguities at each epoch, and adopting a Kalman-filter smoothing while estimating atmospheric delays.

\section{InSAR Processing}

We processed InSAR interferometric pairs from Sentinel-1 and ALOS-2 satellites by using single pair differential SAR interferometry approach (Massonnet and Feigl, 1998): two C-band Sentinel-1 pairs, in ascending and descending geometry from 22 to 28 Dec. 2018 (Figure 2A and $2 \mathrm{~B}$ of the main text, respectively) and a descending L-band ALOS-2 pair from 18 Dec 2018 to 29 Jan 2019 (Figure 2C of the main text). Displacement maps are shown in panel d), e) and f) of Figure 2 of the main text.

We used the Sarscape software (developed by SARMAP() and implemented in the ENVI software) to process all the SAR SLC acquisitions. The Sentinel-1 images were acquired in the Terrain Observation Progressive Scans (TOPS) mode. The analysis of both Sentinel-1 ascending and descending data were performed applying a multi-looking factor equal to 1 for the azimuth and 3 for the range direction, resulting in a final resolution of $15 \mathrm{~m}$ on the ground. The adopted multilooking factors for the ALOS-2 Wide-Swath mode pair were 2 in range and 12 in the azimuth direction respectively with a ground resolution of 30 meters. In Fig. S2, we show the coherence for Sentinel-1 ascending, Sentinel-1 descending and the ALOS-2 descending pairs. 
The Goldstein filter algorithm was employed to reduce the phase noise (Goldstein et al., 1998). We used the 30-m Shuttle Radar Topography Mission (http://www2.jpl.nasa.gov/srtm) digital elevation model for the topography subtraction step (Farr et al., 2007). The Minimum Cost Flow (Costantini, 1998) algorithm was used to unwrap the interferometric phase. A set of Ground Control Points selected in areas considered stable was used to estimate and remove orbital and topographic residuals. Then the unwrapped phase was changed in displacement and geocoded into the WGS84 reference system.

Displacement precision is derived from parameters such as coherence and wavelength, providing an estimate (standard deviation value) of the measurement precision. The higher this value the lower the measurement precision. The formula used for the precision calculation is:

$$
\sqrt{\frac{1-\gamma^{2}}{\gamma^{2}}} \cdot \frac{\lambda}{4 \pi}
$$

Where $\gamma$ is the interferometric coherence and $\lambda$ is the wavelength. Mean uncertainties are \pm 1 $\mathrm{cm}$ for Sentinel-1 pairs and $\pm 2 \mathrm{~cm}$ for ALOS-2 one. Precisions for Sentinel-1 ascending, Sentinel-1 and ALOS-2 descending pairs are reported in Figure S3, S4 and S5, respectively.

In order to validate our InSAR results, we compared estimated SAR displacements to CGPS ones projected along the corresponding (Sentinel-1 ascending, Sentinel-1 descending and ALOS-2 descending) lines of sight (Fig. S6). Correlation indexes are 0.92, 0.98 and 0.97 for Sentinel-1 ascending, Sentinel-1 descending and ALOS-2 descending, respectively, highlighting very good agreements.

\section{Multitemporal InSAR Processing}

The displacement time-series and the mean ground velocities, in the line of sight (LOS) of the satellite geometry, have been obtained adopting by using the Small BAseline Subset (SBAS) approach (Berardino et al., 2002) using the Sarscape software. We processed 29 descending and 29 ascending SAR images by S1 satellites to obtain the mean ground velocities (Figure 3) for the 28 Dec. 2018 - June 2019 and 03 Jan 2019 - 26 June 2019 temporal intervals, respectively. The SBAS algorithm is based on a combination of many SAR differential interferograms that are generated by applying constraints on the temporal and perpendicular baselines. The inversion of the interferometric phase, performed with a Singular Value Decomposition (SVD), produces a ground displacement time series for each coherent pixel, by minimizing possible topographic, atmospheric and orbital artifacts; the achieved accuracy of the displacements can be up to $\sim 1 \mathrm{~mm}$ (Ferretti et al., 2007). The interferometric pairs were selected applying constraints on the maximum orbital separation and the temporal distance between the two passages, in order to minimize spatial and temporal decorrelation effects. We used the 90-m Shuttle Radar Topography Mission digital elevation model for the topography subtraction step (Farr et al., 2007). The analysis of both ascending and descending datasets has been performed applying a multi-looking factor equal to 5 
for the azimuth, and 23 for the range direction, resulting in a final resolution of $90 \mathrm{~m}$. In Fig. S7, we show the coherence for Sentinel-1 ascending and descending multitemporal processing.

Once the unwrapped phase inversion step through the SVD method was completed, a double filtering in space and time (high and low pass) was applied to the removal of the atmospheric artifacts. Then, the displacement time series for each coherent pixel was obtained and the mean ground LOS velocities were estimated fitting, with a least-squares method, the displacement timeseries of each pixel. All the results were geocoded in the WGS84 reference system.

The velocity precision and the multi-temporal coherence maps were calculated to have a measurement of the reliability for the retrieved results. In Figure S8 and S9, the precisions for ascending and descending dataset, respectively.

In order to validate our InSAR results, we compared estimated SAR velocities to CGPS ones, projected along the corresponding (Sentinel-1 ascending and Sentinel-1 descending) lines of sight (Figure S10). Correlation indexes are 0.50 and 0.79 for Sentinel-1 ascending and Sentinel-1 descending, respectively, highlighting a good agreements.

\section{Modeling}

To retrieve dyke and fault parameters, we jointly inverted CGPS and SAR datasets by using an elastic, isotropic and homogeneous model (Okada, 1985). First, we defined two distinct spatial data subsets in order to avoid interferences and trade-off between fault and dyke (Figure S11). Then, we invert the subsets for the dyke and fault source parameters separately. The displacements are then recomputed over the entire area summing the effects of the two sources.

Indeed, two areas can be easily separated observing the fringe patterns in all three SAR interferograms. We observe two distinct butterfly-like fringe patterns: the big one (purple box - dyke intrusion) is located north and only partially superimposed the small one (blue box - earthquake) to the south-east (Figure S11). Here, the contribution due to the dyke intrusion is reasonably negligible, less than one Sentinel fringe $(2.5 \mathrm{~cm})$. Thus, dyke model is only partially crippled and the contribution to the general modeling results is irrelevant. On the other hand, there are numerous concentric fringes around the fault trace (red line) showing the ground deformation due to the earthquake. Earthquake ground deformation pattern seems to be enclosed in the blue box area and the additional displacement due to the dyke intrusion (less than $2.6 \mathrm{~cm}$ ) can be considered irrelevant.

SAR maps are masked on the top of the volcanic edifice, close to the dyke outcropping, where interferograms are decorrelated due to rapid backscattering changes (lava flows, snow, etc.). We applied a $500 \mathrm{~m}$ resampling pass to obtain about 3500 points for each SAR dataset.

We adopted a two-step approach (Atzori et al., 2008) consisting in a non-linear inversion to define the dyke parameters (e.g. north, east, top position, length, width, dip, strike and opening) by means of a non-linear, least-squares inversion algorithm based on the Levemberg-Marquardt 
approach, as described in Atzori et al. (2009); the convention for dip, rake and strike angles is the same as Okada (1985). Values of $30 \mathrm{GPa}$ and 0.25 were assumed for the shear modulus and Poisson's ratio in the half-space, respectively. The parameter uncertainties, best fit and trade-offs (Figure S12) was estimated with 150 restarts of the inversion, adding, each time, a synthetic noise correlated in space according to InSAR data statistical properties (Atzori et al. 2008). Dyke parameters shows an E-NE dipping geometry, spatially overlapping field dyke observations.

We then performed a linear-inversion to determine the opening distribution along the plane fixing all other parameters. Opening distribution along the resulting plane (250x250 $\mathrm{m}$ discretized) highlights a maximum value of about $3 \mathrm{~m}$ in the upper portion, in agreement with on-field observations (Figure 3a). Best fit model RMS values are $0.049 \mathrm{~m}$ for Sentinel-1 ascending, 0.054 $\mathrm{m}$ for Sentinel-1 descending, $0.056 \mathrm{~m}$ for ALOS-2 descending and $0.0028 \mathrm{~m}$ for CGPS datasets.

Uncertainty $(1 \sigma)$ relative to the opening distribution (Figure $4 a$ of the main text) are calculated on the 250x250 m inversion mesh (Figure S13). Values are obtained with the standard rules for error propagation in linear systems, as described in the Appendix B of Atzori et al. (2008). Model resolution values are obtained with the algorithm of Atzori and Antonioli (2011) on a variable-size mesh, which maximizes the model resolution matrix. The width and length of the dyke are adjusted at this stage to contain all patches with significant opening values. The patch sizes, which are automatically determined by the inversion algorithm, vary from $250 \mathrm{~m}$ at depths $2 \mathrm{~km}$ (asl) to 1.3 $\mathrm{km}$ at depths $\geq 3 \mathrm{~km}$ (asl).

For the earthquake source modeling, we directly performed a linear inversion to obtain the slip distribution along the fault plane, constraining the geometry and mechanism from interferogram fringe patterns and global TDMT solution (Figure 2 of the main text). Given the arcuate shape of the fault trace evident in all interferograms, we simplified the fault geometry using four planar segments which surface expressions follow the fault trace (Figure $3 a$ of the main text). Fault segments are discretized in 250×250 m patches and displacement maps are subsampled with 500 $\mathrm{m}$ pass. Best fit model shows RMS values of $0.022 \mathrm{~m}$ for Sentinel- 1 ascending, 0.014 for Sentinel1 descending, 0.022 for ALOS-2 descending and $0.0014 \mathrm{~m}$ for CGPS datasets. About $1 \mathrm{~m}$ of slip is located at $2 \mathrm{~km}$ depth in central fault portion.

Furthermore, we modelled the CGPS dataset spanning the 28 Dec. 2018 - 26 June 2019 time interval by adopting the analytical spheroidal pressure source described in Yang et al. (1988) and by taking into account the effects of topography (Williams and Wadge, 2000). The inversions were performed using the genetic algorithm approach (Tiampo et al., 2000) to minimize the misfit defined as the weighted-root-mean-square error:

$$
\text { WRMSE }=\sqrt{\sum_{i=1}^{n} \frac{\left(\hat{y}_{i}-y_{i}\right)^{2}}{n \sigma_{i}^{2}}}
$$

where $\hat{y}_{i}$ are the predicted measures, $y_{i}$ the observed ones and $\sigma_{i}^{2}$ their associated errors. Values of $30 \mathrm{GPa}$ and 0.25 were assumed for the shear modulus and Poisson's ratio in the half-space, 
respectively. In the computation, both horizontal and vertical CGPS components were inverted by taking into account the weights proportional to the estimated geodetic velocity errors. We discarded all stations located on the middle-to-lower eastern flank of the volcano as affected by vigorous seaward motion during the analyzed time interval. Finally, in order to obtain realistic estimations of the pressure change parameter, we limited the ratio of the pressure change to the shear modulus within the elastic limits of the surrounding rock. Estimation of the uncertainties in best-fitting parameters was performed by adopting a Jackknife sampling method (Efron, 1982). Following Battaglia et al. (2013) the volume change of the ellipsoidal cavity can be approximated by the following empirical formulation:

$$
\Delta V=\frac{3 V \Delta P}{4 \mu}\left(\frac{A^{2}}{3}-c A+d\right)
$$

where $\mathrm{V}$ is the volume of the ellipsoidal cavity, $\Delta P$ is the pressure change, $A=b / a$ represents the geometric aspect ratio between the semi-major axis $a$ and the semi-minor axis $b$ of the Yang et al.'s (1988) analytical pressure source. Constants $c$ and d are determined by the polynomial best fit to the numerical solutions provided from Amoruso and Crescentini (2009) and have values of 0.7 and 1.37, respectively. The optimal model parameters (WRMSE $=61.3$ ) along with associated uncertainties are reported in Table S1.

\section{Static stress change analysis}

We studied the relationships between eruptive, seismic and gravitative events by means of the Coulomb Failure Function (hereinafter $\triangle C F F$; e.g., Harris, 1998). Neglecting the contribution of the underground fluid pressure, Coulomb failure stress is defined as:

$$
\mathrm{CFF}=\boldsymbol{\tau}+\left(\mu^{\prime} \sigma\right)-\mathrm{S}
$$

where $\boldsymbol{\tau}$ is the shear traction along the target fault plane, $\sigma$ is the normal traction (positive for traction), $\mu^{\prime}$ is the apparent friction coefficient and $S$ is the rock cohesion, considered constant over time. $\mu^{\prime}$ is kept fixed at a value of 0.4. Being the absolute stress values are not known, we evaluate the Coulomb stress variation. With $S$ constant at a first order approximation, the $\Delta C F F$ then becomes:

$$
\Delta \mathrm{CFF}=\Delta \tau+\mu^{\prime} \Delta \sigma
$$

First, we evaluated the static stress variation induced by the dyke opening on the $26 \mathrm{Dec}$. fault plane and along the detachment surface below the eastern flank of the volcano. Such a detachment surface is constrained by the sedimentary/volcanic deposit interface defined by $V_{P}=3.5$ $\mathrm{km} / \mathrm{s}$ surface in the tomographic model, also in agreement with Branca and Ferrara (2013) results constrained by geoelectric and borehole prospecting. Results show a maximum value of $0.16 \mathrm{MPa}$ of stress increase induced by the dyke opening on the fault (Figure $4 \mathrm{C}$ ), a value that is small but 
227 not negligible with respect to the minimum stress-variation triggering threshold $(0.01 \mathrm{MPa})$

228 (Hardebeck et al., 1998).

229 Second, we evaluate how the sliding of the flank interacts with dyke intrusion, calculating the 230 pressure variation along a vertical profile beneath the summit area caused by the long-term stable 231 sliding. Assuming a rigid, steady, movement of the collapsing block at $4.5 \mathrm{~cm} / \mathrm{yr}$, we inferred a 232 pressure decrease of about $1 \mathrm{MPa} / \mathrm{yr}$ in the upper portion of the volcano, $1.4 \mathrm{Km}$ from the top 233 (Figure 4D). Considering a post intrusion acceleration up to $15 \mathrm{~cm} / \mathrm{yr}$ velocity, as observed, we 234 obtain the same pattern of pressure variation, with values up to $3 \mathrm{MPa} / \mathrm{yr}$ (Figure 4D).

\section{Tomographic constraints}

237 In order to constrain the eastern flank sliding plane geometry, we use the seismic VP 238 tomography model obtained by Giampiccolo et al. (2020). The detachment is assumed to be 239 located at the volcanic-sedimentary interface (Palano, 2016) with a geometry constrained by iso240 velocity (VP $=3.5 \mathrm{~km} / \mathrm{s}$ ) surface (Figure S14). Identified surface geometry is consistent with base 241 of volcanic deposits as identified by Branca and Ferrara, 2013 based on geologic data. In VP 242 velocity models, we also identified a sharp east-dipping scarp, representing weak zones within the 243 sedimentary basement, laying in vertical continuity with the modeled dyke (Figure S14). 


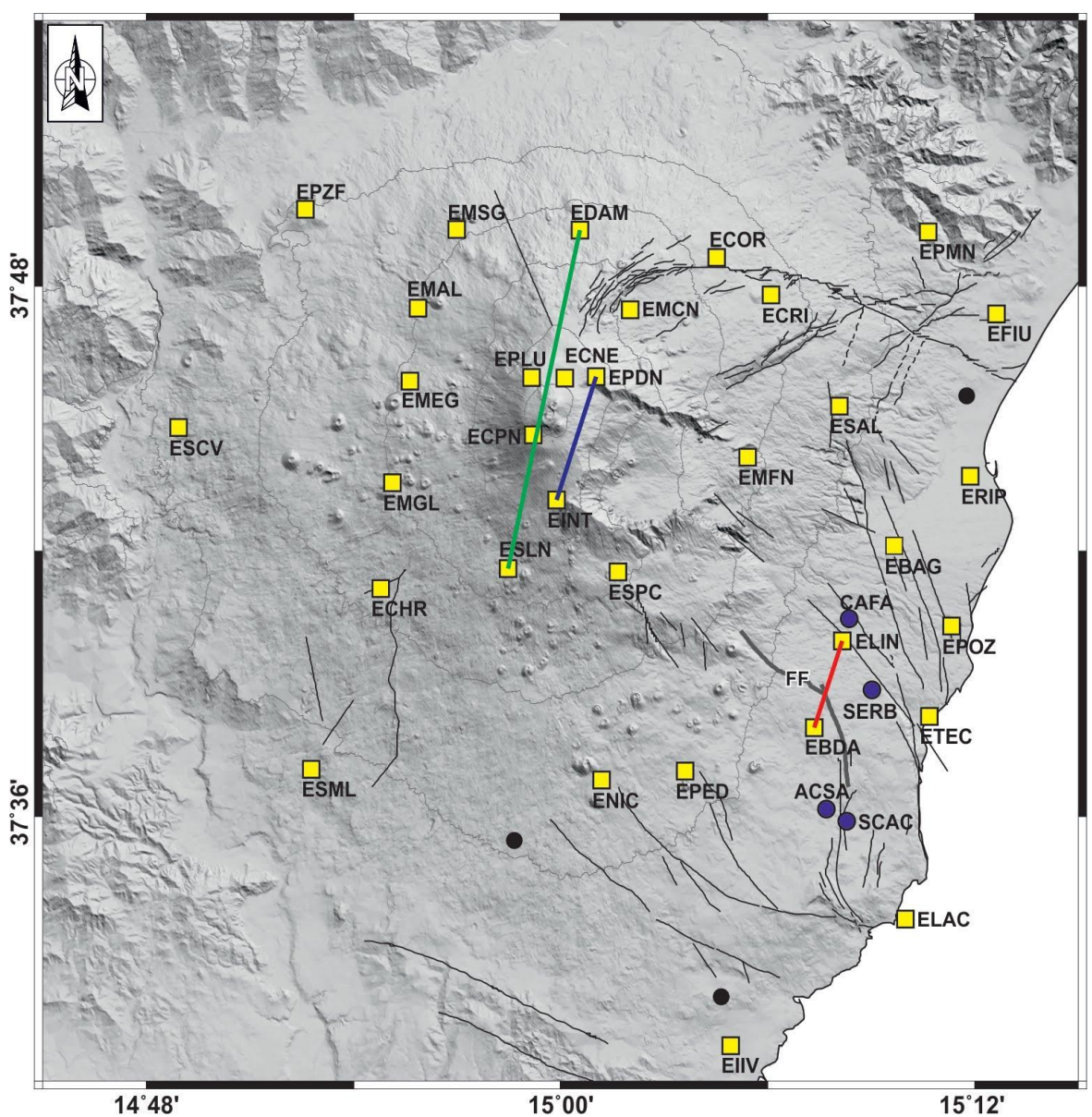

Figure S1. Topographic map of Mt. Etna with location of the CGPS stations used in this study. The EPDNEINT, EBDA-ELIN (reported in Fig. 1C) and EDAM-ESLN (reported in Fig. 3C) baselines, are traced with a blue, a red and a green line, respectively. FF, Fiandaca fault system.
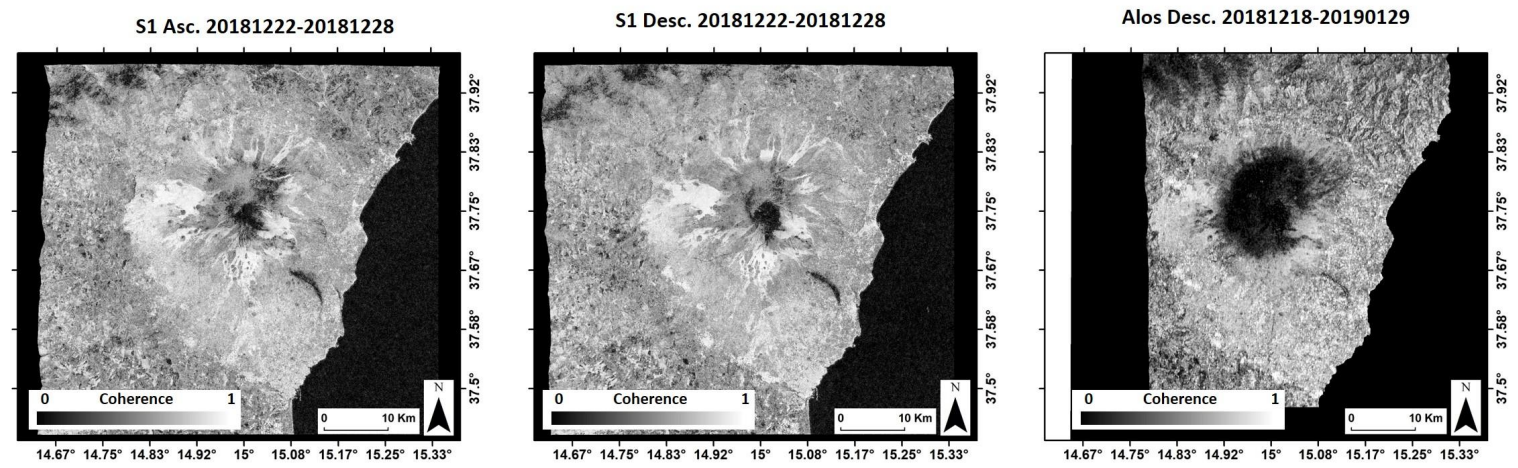

Figure S2. Coherence map for Sentinel-1 ascending, Sentinel-1 descending and the ALOS-2 descending pairs. 


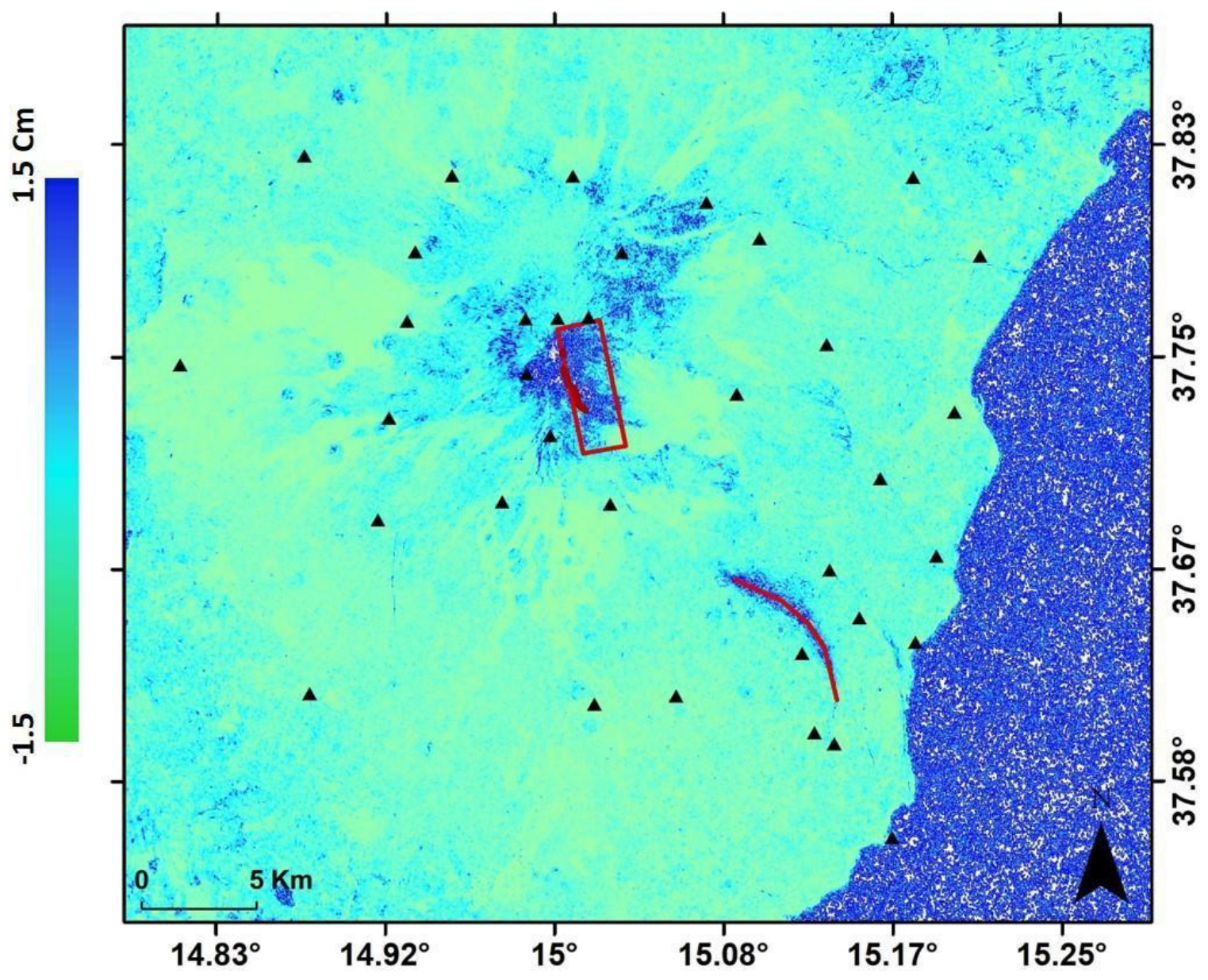

257 Figure S3. Measurement precision for Sentinel-1 ascending 22/12 - 28/12/2018 pair. The surface projection of modelled dyke and faults (red lines) are also reported. 


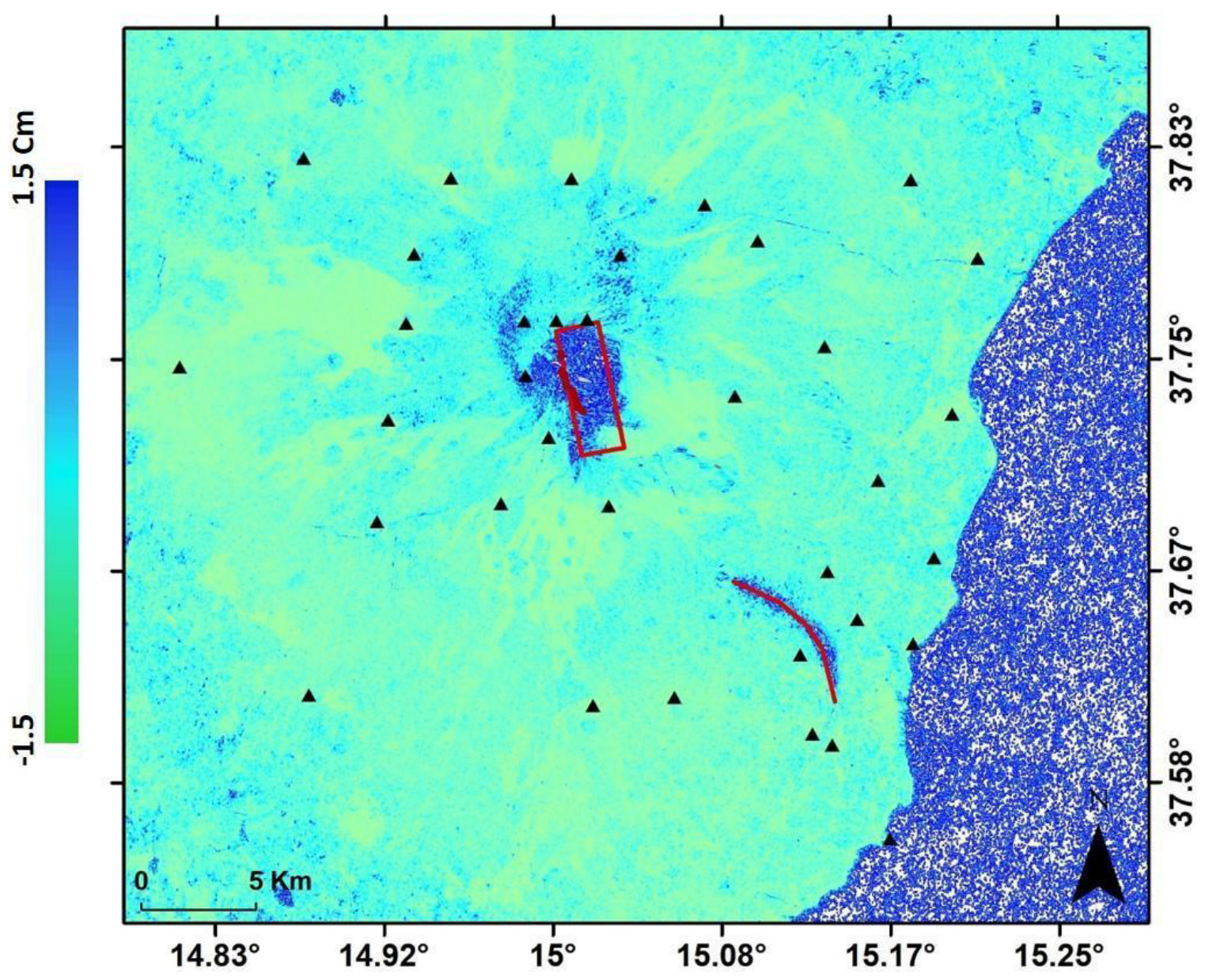

260

Figure S4. Measurement precision for Sentinel-1 descending 22/12 - 28/12/2018 pair. The surface 262 projection of modelled dyke and faults (red lines) are also reported. 


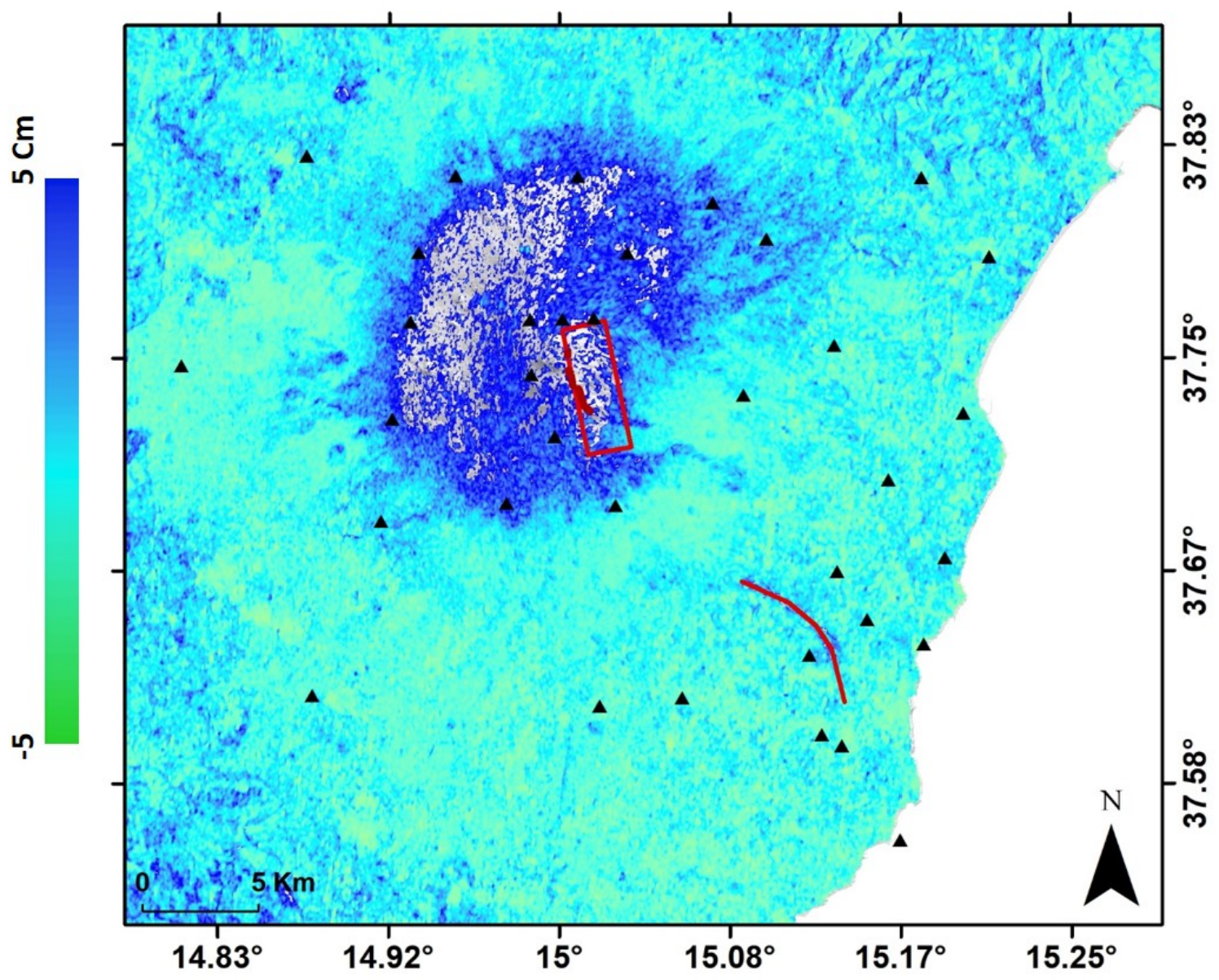

Figure S5. Measurement precision for ALOS-2 descending 18/12 - 29/101/2019 pair. The surface projection of modelled dyke and faults (red lines) are also reported.
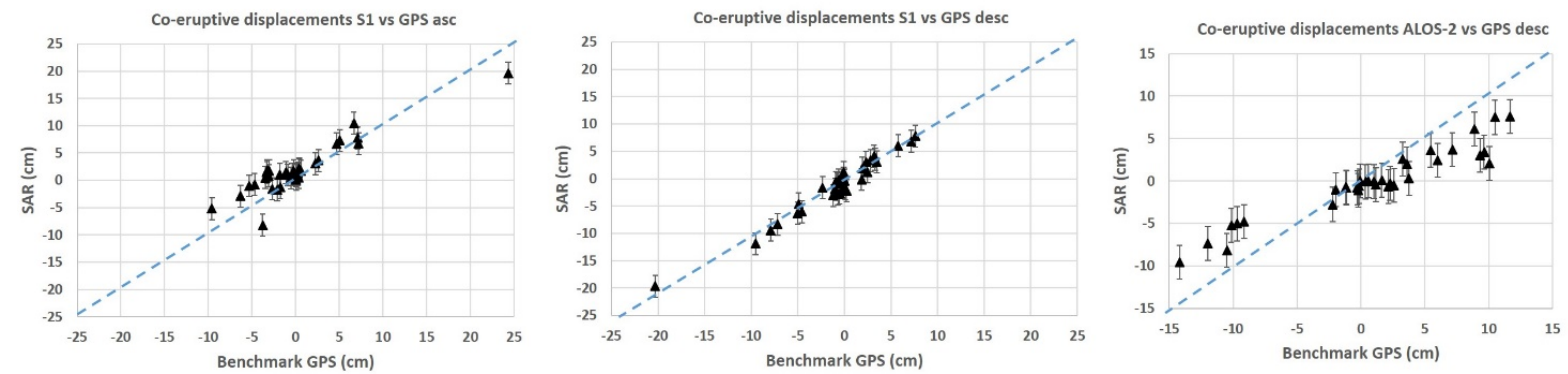

Figure S6. Scatterplots comparing SAR and CGPS displacements for Sentinel-1 ascending, Sentinel-1 descending and ALOS-2 descending co-eruptive datasets. CGPS data are projected along the corresponding lines of sight. 


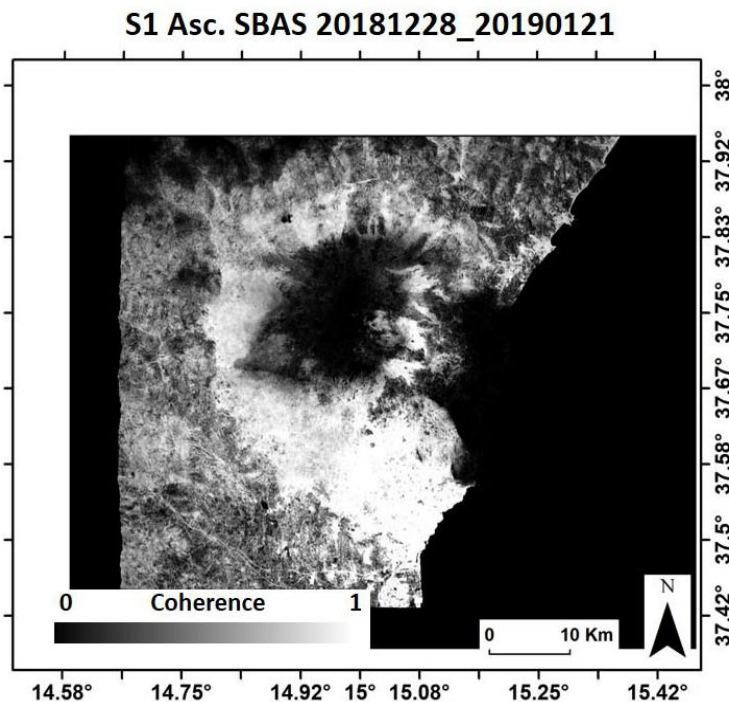

S1 Desc. SBAS 20190103_20191217

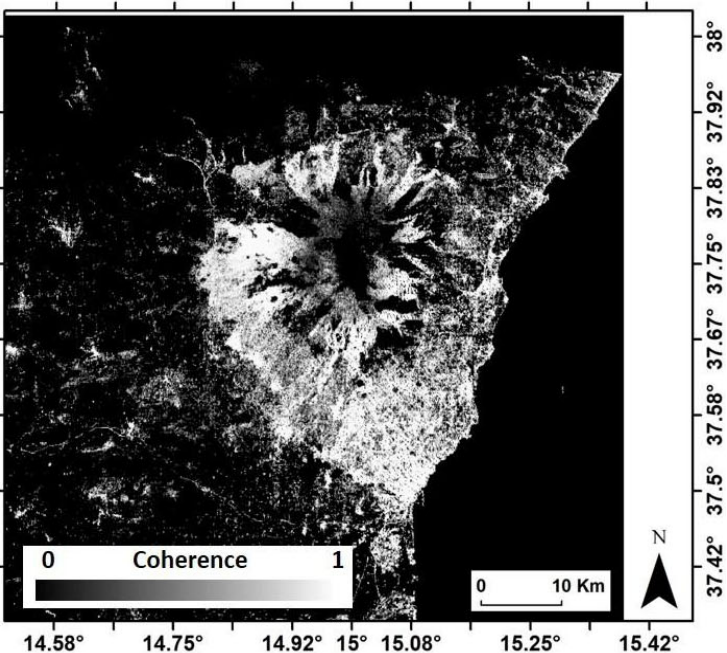

Figure S7. Coherence map for Sentinel-1 ascending and descending multitemporal processing.

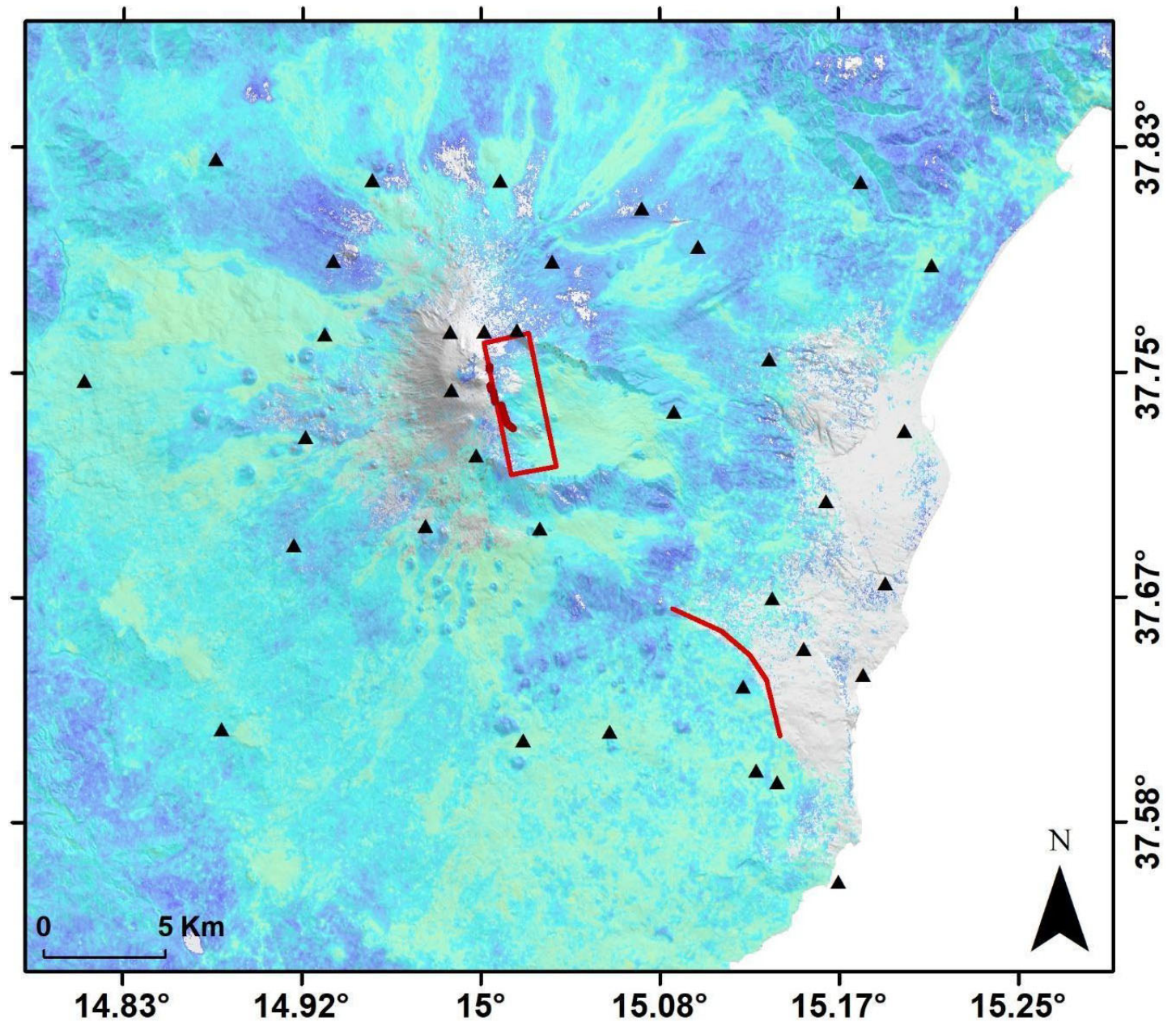

Figure S8. Measurement precision for Sentinel-1 ascending multitemporal process. The surface projection of modelled dyke and faults (red lines) are also reported. 


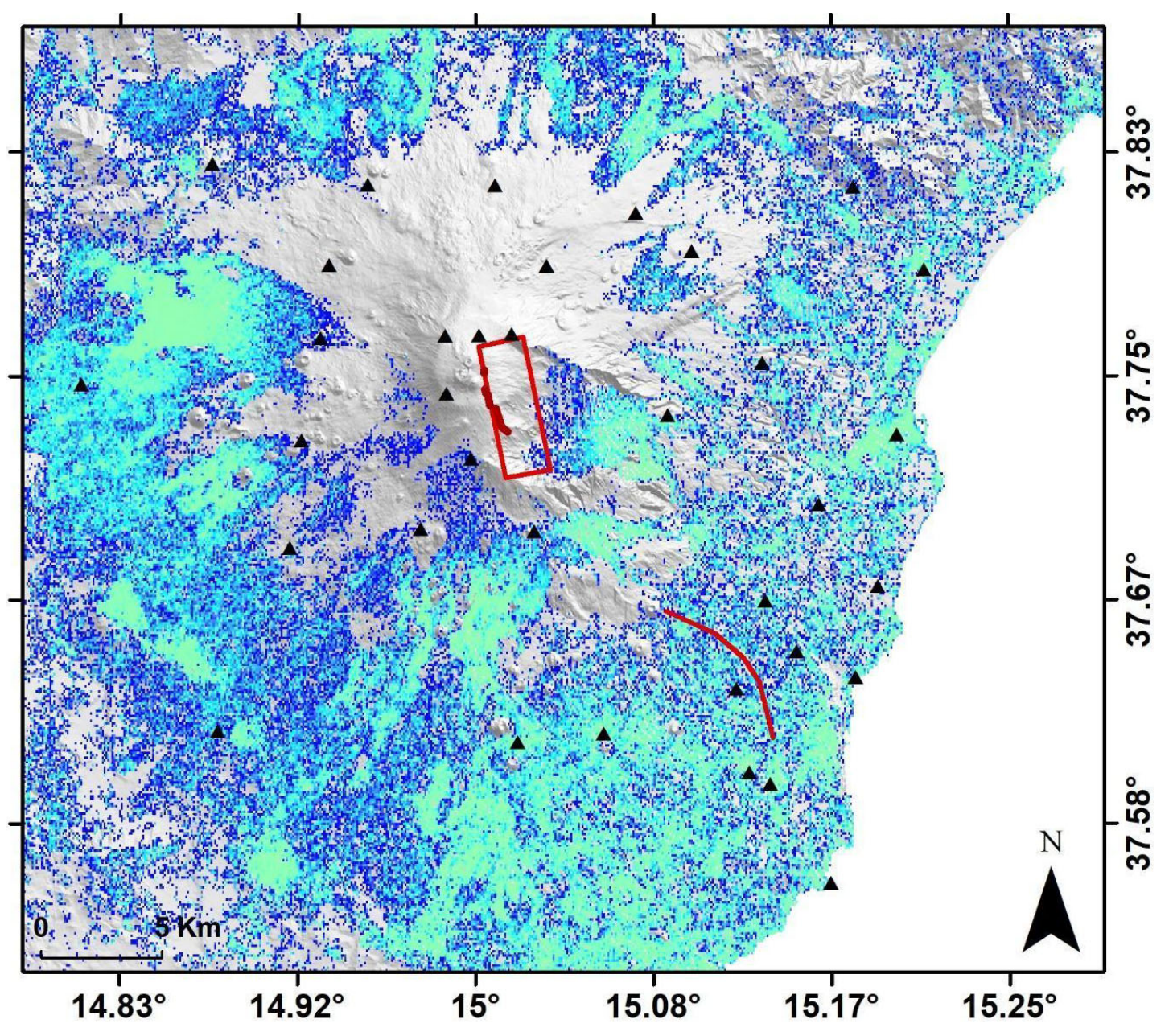

Figure S9. Measurement precision for Sentinel-1 ascending multitemporal process. The surface projection of
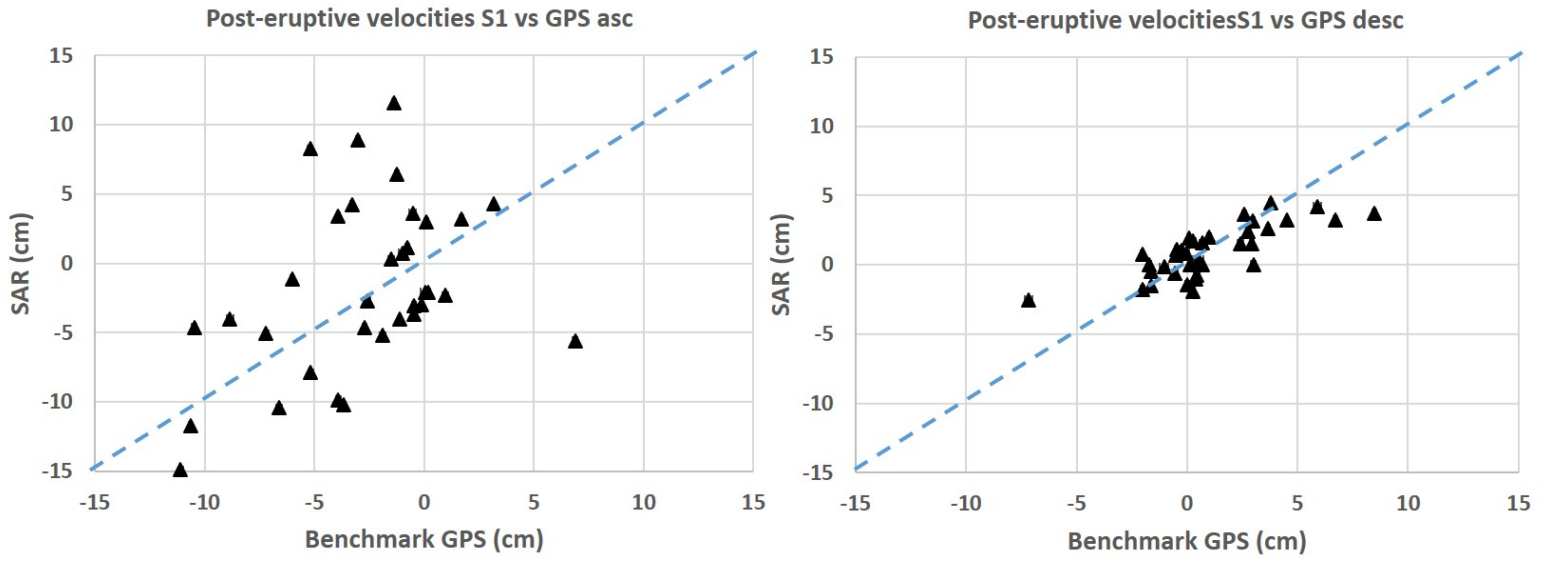
Figure S10. Scatterplots comparing SAR and CGPS velocities for Sentinel-1 ascending and Sentinel-1 descending post-eruptive datasets. CGPS data are projected along the corresponding lines of sight.

289
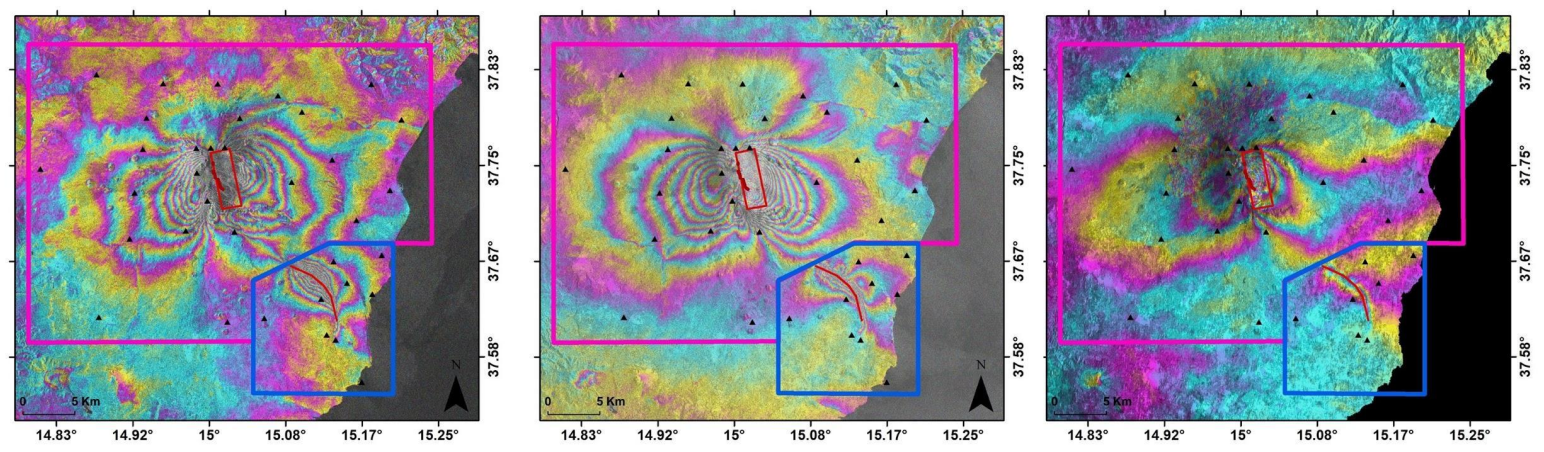

Figure S11. Left to right: Sentinel-1 ascending, Sentinel-1 descending and ALOS-2 descending interferograms; purple and blue boxes limit the areas where ground deformation is related to the dyke intrusion and to the earthquake, respectively. 

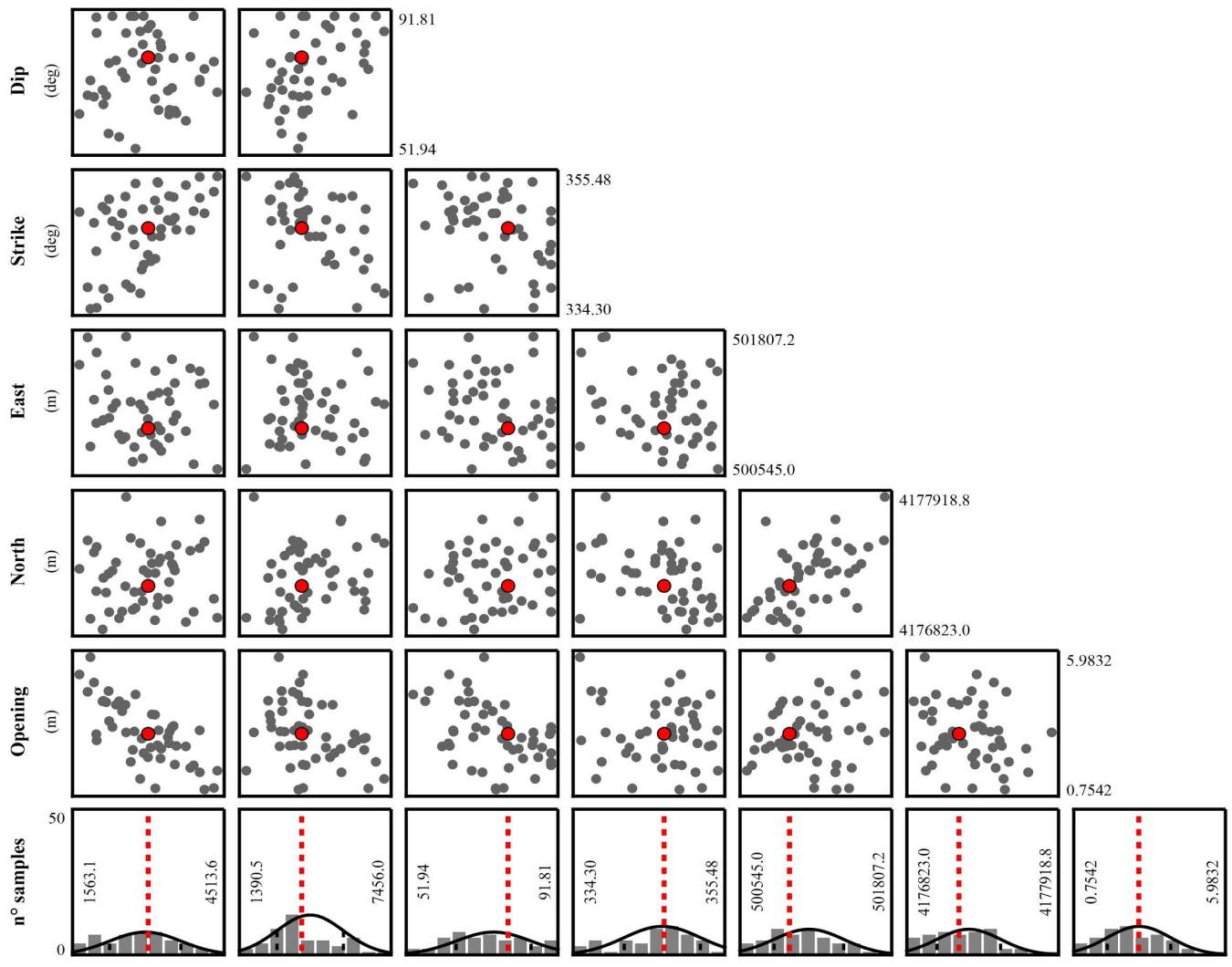

Length

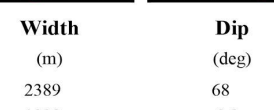

$\begin{array}{rr} & (\mathrm{m}) \\ \text { Best-fit } & 2359 \\ \text { St. Dev. } & 692\end{array}$

1329

9.9

Figure S12. Best fit, standard deviations $(\sigma)$ and trade-offs of inverted parameters. Coordinates are in UTM-
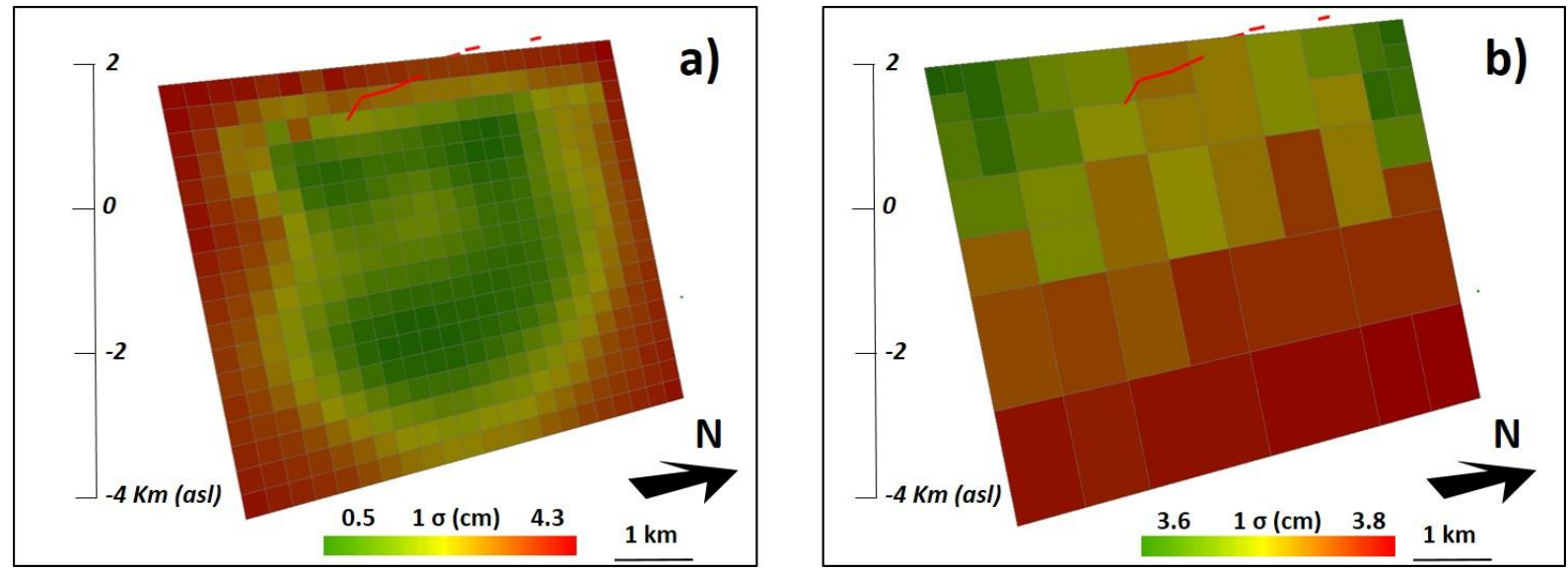

Figure S13. a) Uncertainty $(1 \sigma)$ relative to the opening distribution of Figure 4A (main text). b) Model resolution and uncertainty on a variable-size mesh, which maximizes the model resolution matrix. 


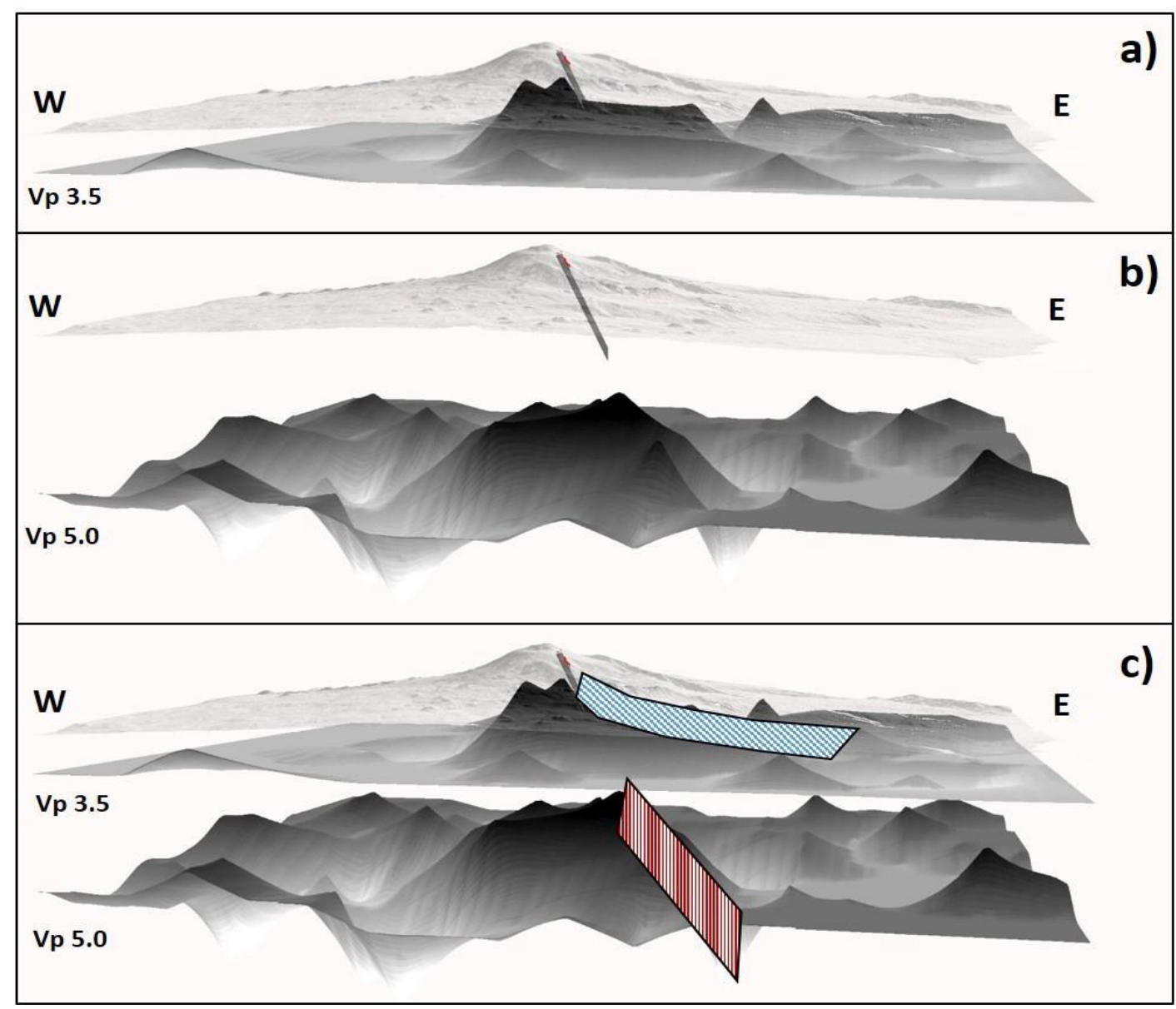

Figure S14. 3D W-E-profiles showing the $P$-wave iso-velocity surfaces, $V_{P}=3.5 \mathrm{Km} / \mathrm{s}(\mathrm{a})$ and $V_{P}=5.0 \mathrm{Km} / \mathrm{s}$ (b) coming from recent tomographic data (Giampiccolo et al., 2020) and representing the volcanicsedimentary deposit interface and the top of the carbonate basement, respectively. c) a 3D view of both 3.5 and $5.0 \mathrm{Km} / \mathrm{s}$ P-wave iso-velocity surfaces where we identified a sharp east-dipping scarp in the sedimentary basement (in red) and the eastern flank sliding plane (in blue). The modelled dyke is reported in all panels.

\begin{tabular}{|l|c|}
\hline Parameters & Estimated values \pm uncertainty \\
\hline Easting $(\mathrm{m})$ & $497910 \pm 372$ \\
\hline Northing $(\mathrm{m})$ & $4180038 \pm 462$ \\
\hline Depth $(\mathrm{m} \mathrm{bsl})$ & $6486 \pm 538$ \\
\hline $\mathrm{a}(\mathrm{m})$ & $1762 \pm 95$ \\
\hline b/a ratio & $0.25 \pm 0.02$ \\
\hline Azimuth $\left(^{\circ}\right)$ & $214 \pm 11$ \\
\hline Dip $\left(^{\circ}\right)$ & $57 \pm 4$ \\
\hline$\Delta \mathrm{P}\left(10^{8} \mathrm{~Pa}\right)$ & $3.61 \pm 0.2$ \\
\hline
\end{tabular}


Table S1. Parameters of the modeled source for post-event time interval (28 Dec. 2018 - 26 Jun. 2019). Coordinates are UTM33N.

\section{REFERENCES}

Amoruso, A., and Crescentini, L., 2009, Shape and volume change of pressurized ellipsoidal cavities from deformation and seismic data: Journal of Geophysical Research: Solid Earth, v. 114, B02210, doi:10.1029/2008JB005946.

Atzori, S., and Antonioli A., 2011, Optimal fault resolution in geodetic inversion of coseismic data: Geophysical Journal International, v. 185, p. 529-538, doi:10.1111/j.1365-246X.2011.04955.x.

Atzori, S., Manunta, M., Fornaro, G., Ganas, A. and Salvi, S., 2008, Postseismic displacement of the 1999 Athens earthquake retrieved by the Differential Interferometry by Synthetic Aperture Radartime series: Journal of Geophysical Research, v. 113, B09309, doi:10.1029/2007JB005504.

Atzori, S., et al., 2009, Finite fault inversion of DInSAR coseismic displacement of the 2009 L'Aquila earthquake (central Italy): Geophysical Research Letters, v. 36 (15), L15305, doi:10.1029/2009GL039293.

Battaglia, M., Cervelli, P. F., and Murray, J. R., 2013, DMODELS: A MATLAB software package for modeling crustal deformation near active faults and volcanic centers: Journal of Volcanology and Geothermal Research, v. 254, p. 1-4, doi:10.1016/j.jvolgeores.2012.12.018.

Berardino, P., Fornaro, G., Lanari, R., and Sansosti, E., 2002, A new algorithm for surface deformation monitoring based on small baseline differential SAR interferograms: IEEE Transactions on Geoscience and Remote Sensing, v. 40, p. 2375-2383, doi:10.1109/TGRS.2002.803792.

Böhm, J., Niell, A., Tregoning, P., and Schuh H., 2006, Global Mapping Function (GMF): A new empirical mapping function based on data from numerical weather model data: Geophysical Research Letters, v. 33, B02406, doi:10.1029/2005GL025546.

Branca, S., and Ferrara, V., 2013, The morphostructural setting of Mount Etna sedimentary basement (Italy): Implications for the geometry and volume of the volcano and its flank instability: Tectonophysics, v. 586, p. 46-64, doi:10.1016/j.tecto.2012.11.011.

Costantini, M., 1998, A novel phase unwrapping method based on network programming: IEEE Transactions on Geoscience and Remote Sensing, v. 26 (3), p. 813-821, doi:10.1109/36.673674.

Efron, B, 1982, The jackknife, the bootstrap and other resampling plans. Philadelphia, PA: Society for Industrial and Applied Mathematics.

Farr, T. G., et al., 2007, The Shuttle Radar Topography Mission: Reviews of Geophysics, v. 45, RG2004, doi:10.1029/2005RG000183.

Ferretti, A., Monti-Guarnieri, A. V., Prati, C., Rocca, F., and Massonnet, D., 2007, INSAR Principles A. ESA publications.

Giampiccolo, E., Cocina, O., De Gori, P., and Chiarabba, C., 2020, Dyke intrusion and stressinduced collapse of volcano flanks: The example of the 2018 event at Mt. Etna: Nature Scientific Reports, v. 10, 6373, doi:10.1038/s41598-020-63371-3. 
Goldstein, R. M., and Werner, C. L., 1998, Radar interferogram filtering for geophysical applications. Geophysical Research Letters, v. 25(21), p. 4035-4038.

Hardebeck, J. L., Nazareth, J. J., and Hauksson, E., 1998, The static stress change triggering model: Constraints from two southern California aftershock sequences: Journal of Geophysical Research, v. 103 (B10), p. 24427-24437, doi:10.1029/98JB00573.

Harris, R. A., 1988, Introduction to special section: Stress triggers, stress shadows, and implications for seismic hazard: Journal of Geophysical Research, v. 103, p. 347-358, doi: 10.1029/98JB01576.

Herring, T. A., King, R. W., Floyd, M. A., and McClusky, S. C., 2018, Introduction to GAMIT/GLOBK, release 10.70., Cambridge: Massachusetts Institute of Technology.

Massonnet, D., and Feigl, K. L., 1988, Radar interferometry and its application to changes in the Earth's surface: Reviews of geophysics, v. 36(4), p. 441-500, doi:10.1029/97RG03139.

Okada, Y., 1985, Surface deformation due to shear and tensile faults in a half-space: Bulletin of the Seismological Society of America, v. 75(4), 1135-1154.

Palano, M. et al., 2010, Etn@ref, a geodetic reference frame for Mt. Etna GPS networks: Annals of Geophysics, 53(4), 48-79, doi:10.4401/af-4879.

Palano, M. Episodic slow slip events and seaward flank motion at Mt. Etna volcano (Italy): Journal of Volcanology and Geothermal Research, v. 324, p. 8-14, doi:10.1016/j.jvolgeores.2016.05.010.

Saastamoinen, J., 1972, Contribution to the theory of atmospheric refraction: Bulletin Géodésique, v. 105 (1), p. 279-298, doi:10.1007/BF02521844.

Tiampo, K. F., Rundle, J. B., Fernandez, J., \& Langbein, J. O., 2000, Spherical and ellipsoidal volcanic sources at Long Valley caldera, California, using a genetic algorithm inversion technique: Journal of Volcanology and Geothermal Research, v. 102, p. 189-206, doi:10.1016/S0377-0273(00)00185-2.

Williams, C. A., and Wadge, G., 2000, An accurate and efficient method for including the effects of topography in three-dimensional elastic models of ground deformation with applications to radar interferometry: Journal of Geophysical Research, v. 105 (B4), p. 8103-8120, doi:10.1029/1999JB900307

Wübbena, G., 1998, GPS carrier phases and clock modeling. In E. Groten and R. Strauss (Eds.), GPS-Techniques Applied to Geodesy and Surveying, Proceedings of the International GPSWorkshop, Darmstadt. Lecture Notes in Earth Sciences, (vol. 19), Berlin, Springer Verlag.

Yang, X. M., Davis, P. M., \& Dieterich, J. H., 1988, Deformation from inflation of a dipping finite prolate spheroid in an elastic half-space as a model for volcanic stressing: Journal of Geophysical Research, v. 93 (B5), p. 4249-4257, doi:10.1029/JB093iB05p04249. 